\title{
Front Matter: Volume 6788
}

, "Front Matter: Volume 6788," Proc. SPIE 6788, MIPPR 2007: Pattern Recognition and Computer Vision, 678801 (15 November 2007); doi: 10.1117/12.781925

SDIE Event: International Symposium on Multispectral Image Processing and SPIE. Pattern Recognition, 2007, Wuhan, China 


\title{
PROCEEDINGS OF SPIE
}

\section{MIPPR 2007}

\section{Pattern Recognition and Computer Vision}

\author{
S. J. Maybank \\ Mingyue Ding \\ F. Wahl \\ Yaoting Zhu \\ Editors
}

15-17 November 2007

Wuhan, China

Sponsored by

State Key Laboratory for Multi-spectral Information Processing Technologies (China)

Chinese Education Ministry Key Laboratory for Image Processing and Intelligence Control (China)

Huazhong University of Science and Technology (China)

Technical Sponsor

SPIE

Cooperating Organizations

Institute of Automation, Chinese Academy of Sciences (China) • Wuhan University (China)

Supported by

National Natural Science Foundation of China (China) • Education Ministry of China (China)

Published by

SPIE

Volume 6788 
The papers included in this volume were part of the technical conference cited on the cover and title page. Papers were selected and subject to review by the editors and conference program committee. Some conference presentations may not be available for publication. The papers published in these proceedings reflect the work and thoughts of the authors and are published herein as submitted. The publisher is not responsible for the validity of the information or for any outcomes resulting from reliance thereon.

Please use the following format to cite material from this book:

Author(s), "Title of Paper," in MIPPR 2007: Pattern Recognition and Computer Vision, edited by S. J. Maybank, Mingyue Ding, F. Wahl, Yaoting Zhu, Proceedings of SPIE Vol. 6788 (SPIE, Bellingham, WA, 2007) Article CID Number.

ISSN 0277-786X

ISBN 9780819469526

Published by

SPIE

P.O. Box 10, Bellingham, Washington $98227-0010$ USA

Telephone +1 3606763290 (Pacific Time) · Fax +1 3606471445

SPIE.org

Copyright (c) 2007, Society of Photo-Optical Instrumentation Engineers

Copying of material in this book for internal or personal use, or for the internal or personal use of specific clients, beyond the fair use provisions granted by the U.S. Copyright Law is authorized by SPIE subject to payment of copying fees. The Transactional Reporting Service base fee for this volume is $\$ 18.00$ per article (or portion thereof), which should be paid directly to the Copyright Clearance Center (CCC), 222 Rosewood Drive, Danvers, MA 01923. Payment may also be made electronically through CCC Online at copyright.com. Other copying for republication, resale, advertising or promotion, or any form of systematic or multiple reproduction of any material in this book is prohibited except with permission in writing from the publisher. The CCC fee code is 0277-786X/07/ \$18.00.

Printed in the United States of America.

Publication of record for individual papers is online in the SPIE Digital Library.

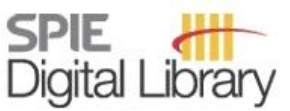

SPIEDigitalLibrary.org

Paper Numbering: Proceedings of SPIE follow an e-First publication model, with papers published first online and then in print and on CD-ROM. Papers are published as they are submitted and meet publication criteria. A unique, consistent, permanent citation identifier (CID) number is assigned to each article at the time of the first publication. Utilization of CIDs allows articles to be fully citable as soon they are published online, and connects the same identifier to all online, print, and electronic versions of the publication. SPIE uses a six-digit CID article numbering system in which:

- The first four digits correspond to the SPIE volume number.

- The last two digits indicate publication order within the volume using a Base 36 numbering system employing both numerals and letters. These two-number sets start with $00,01,02,03,04,05$, 06, 07, 08, 09, OA, OB ... 0Z, followed by 10-1Z, 20-2Z, etc.

The CID number appears on each page of the manuscript. The complete citation is used on the first page, and an abbreviated version on subsequent pages. Numbers in the index correspond to the last two digits of the six-digit CID number. 


\section{Contents}

$\begin{aligned} & \text { xi } \text { Symposium Committees } \\ & \text { xiii Preface }\end{aligned}$

\section{PATTERN RECOGNITION AND COMPUTER VISION}

678802 Audio-visual affective expression recognition (Invited Paper)

T. S. Huang, Z. Zeng, Univ. of Illinois at Urbana-Champaign (USA)

$678803 \quad$ Audio-visual gender recognition (Invited Paper)

M. LiU, X. XU, T. S. Huang, Univ. of Illinois at Urbana-Champaign (USA)

678804 Rotation invariant texture classification based on Gabor wavelets

X. Xie, J. Lu, Tsinghua Univ. (China); J. Gong, N. Zhang, China Electronic System Engineering Co. (China)

678805 Fuzzy recognition method for radar target based on KPCA and SVDD

L. Guo, H. Xiao, Q. Fu, National Univ. of Defense Technology (China)

678806 Group clustering and its visualization in group support systems

C. Xiong, Huazhong Univ. of Science and Technology (China) and Hubei Univ. of Technology (China); D. Li, L. Jin, Huazhong Univ. of Science and Technology (China); X. Sun, Huazhong Univ. of Science and Technology (China) and Hubei Univ. of Technology (China)

678807 Scene classification using low-level feature and intermediate feature P. Zeng, J. Wen, L.-D. Wu, National Univ. of Defense Technology (China)

678808 New method of 3D point reconstruction from monocular camera L. Qi, X. WU, Y. Zhang, J. Yang, Shandong Univ. (China)

678809 3D scene reconstruction based on the panoramic camera system of the lunar rover 6788-07

C. Jiao, M. Gao, Y. Shi, Northwestern Polytechnical Univ. (China)

6788 0A Probability output modeling for support vector machines

$X$. Zhang, Yangtze Univ. (China) and Key Lab. of Exploration Technologies for Oil and Gas Resources, Ministry of Education (China); X. Xiao, Yangtze Univ. (China); J. Tian, J. Liu, Huazhong Univ. of Science and Technology (China)

$6788 \mathrm{OB} \quad$ Binocular stereo vision system design for lunar rover

J. Chu, Nanchang Univ. of Aeronautics (China) and National Observatories (China);

C. Jiao, Northwestern Polytechnical Univ. (China); H. Guo, Nanchang Univ. (China);

X. Zhang, National Observatories (China) 
6788 OC Shape classification using hidden Markov model and structural feature

B. Xie, Soochow Univ. (China); Z. Wang, Univ. of Sydney (Australia); J. Wang, Soochow Univ. (China) and Univ. of Sydney (Australia)

6788 OD Research on target recognition techniques of radar networking based on fuzzy mathematics

C. Guan, G. Wang, NAEl (China); C. Guan, The Chinese People's Liberation Army (China);

J. Pan, NAEI (China)

$6788 \mathrm{OE} \quad 3 \mathrm{D}$ profilometry reconstructs based on two-frequency projecting grating method Y. Fu, Nanchang Hangkong Univ. (China) and Huazhong Univ. of Science and Technology (China); W. Zou, H. Xiao, M. Chai, Nanchang Hangkong Univ. (China)

6788 OF Novel cross correlation method for redshift determination of galaxy spectra F. Duan, P. Guo, M. Zhou, Beijing Normal Univ. (China)

6788 OG Research on the city's water affairs dispatchment system based on rough sets theory 6788-14

X. Li, J. Hua, C. Li, Y. Li, Air Force Engineering Univ. (China)

$6788 \mathrm{OH} \quad$ Texture classification of aerial image based on Bayesian networks

L. Ma, Wuhan Univ. (China); H. Yu, China Institute of Water Resources and Hydropower Research (China); J. Li, China Univ. of Mining and Technology (China); H. Chen, Wuhan Univ. (China)

6788 Ol Recognizing license plate character based on simplified PCNN J. Wu, Z. Xiao, Tianjin Polytechnic Univ. (China)

6788 OJ Research of 3D model construction and visualization of complicated objects in 3D cyber-city

P. Chen, L. Meng, Wuhan Univ. (China)

6788 OK Visual inspection of industrial sheet metal part with CAD data M. Tang, Z. Zhang, J. Zhang, Wuhan Univ. (China)

$6788 \mathrm{OL} \quad$ Novel algorithm for iris localization

Y. Wang, T. Liu, L. Liu, Tianjin Univ. (China)

$67880 \mathrm{M}$ Study of the model of probability-based covering algorithm Y. Zhou, Y. Xie, L. Zhang, Anhui Univ. (China)

$67880 \mathrm{~N}$ Texture image recognition based on modified probabilistic neural network D. Yang, S. Xiao, J. Jiang, Changsha Univ. of Science and Technology (China)

$678800 \quad$ Improved neighborhood preserving embedding approach R. Zhi, Q. Ruan, Beijing Jiaotong Univ. (China)

6788 OP Time-critical adaptive visualization method of 3D city models Y. Zhang, Q. Zhu, M. Hu, Wuhan Univ. (China)

$67880 Q \quad$ Textural defect detection using a revised ant colony clustering algorithm C. Zou, L. Xiao, B. Wang, Huazhong Univ. of Science and Technology (China) 
Research on methodology of image semantic understanding based on generalized computing

Y. Zhang, Wenzhou Univ. (China); M. Yao, Z. Yuan, Zhejiang Univ. (China) and Wuhan Univ. (China)

6788 OS People in videos from people in pictures

J. Abbas, C. K. Dagli, T. S. Huang, Univ. of Illinois at Urbana-Champaign (USA)

6788 OT Simulation of sea surface images in the infrared and similarity evaluation

J. Yang, Y. Wang, T. Zhang, Huazhong Univ. of Science and Technology (China)

6788 OU Line-based logo recognition through a web-camera

X. Chen, Y. Wang, X. Feng, Institute of Automation (China)

6788 OV Building detection from LIDAR and images in urban areas

H. Guan, F. Deng, J. Zhang, Wuhan Univ. (China)

6788 OW Classification method based on KCCA

Z. Wang, Huazhong Univ. of Science and Technology (China) and Wuhan Univ. of Technology (China); G. Zhang, G. Zhao, Huazhong Univ. of Science and Technology (China)

6788 OX Exploiting pair-wise constraints between parts for human tracking J. Zhang, X. Shen, J. Zhou, G. Rong, Tsinghua Univ. (China)

6788 OY Object tracking with revised SMOG model

H. Wang, M. Ren, J. Yang, Nanjing Univ. of Science and Technology (China)

$67880 Z$ Self calibration of camera with non-linear imaging model

W. Hou, Huazhong Univ. of Science and Technology (China); T. Shang, Wuhan Univ.

(China); M. Ding, Huazhong Univ. of Science and Technology (China)

678810 Geo-registration and mosaic of UAV video for quick-response to forest fire disaster J. Wu, Guilin Univ. of Electronic Technology (China); Z. Dong, China Institute of Geotechnical Investigation and Surveying (China); Z. Liu, Beijing Normal Univ. (China); G. Zhou, Old Dominion Univ. (USA)

678811 Topologically clustering: a method for discarding mismatches Y. Wang, D. Zhang, C. Gao, J. Tian, Huazhong Univ. of Science and Technology (China)

678812 Multi-scale bi-domain Bayesian classifier designed for infrared image segmentation Q. Zhang, L. Guo, Northwestern Polytechnical Univ. (China)

678813 Panning and multi-baseline digital close-range photogrammetry T. Ke, Z. Zhang, J. Zhang, Wuhan Univ. (China)

$678814 \quad$ JBC: joint boost clustering method for synthesis aperture radar images M. Liu, C. He, G.-S. Xia, X. Xu, H. Sun, Wuhan Univ. (China) 
$678815 \quad$ New image distance and its application in object recognition

B. Yang, J. Zhang, D. Shen, J. Tian, Y. Liu, Huazhong Univ. of Science and Technology (China)

678816 Video shot classification with concept detection

Z. Ji, Y. SU, Tianjin Univ. (China)

678817 Classification of lunar soil from reflectance spectrum by PCA and SVM

$X$. Zhang, National Astronomical Observatories (China) and Graduate Univ. of Chinese Academy of Sciences (China); M. Huang, National Astronomical Observatories (China); J. Chu, National Astronomical Observatories (China) and Nanchang Univ. of Aeronautics (China); C. Li, National Astronomical Observatories (China)

678818 Image merging method based on characteristic objects' distributing statistic feature P. Wang, W. Zhou, J. WU, J. Chen, Huazhong Univ. of Science and Technology (China)

678819 Analysis of image quality based on perceptual preference L. Xue, Shandong Univ. of Science and Technology (China); Y. Hua, Shenyang Institute of Technology (China); G. Zhao, Huazhong Univ. of Science and Technology (China); Y. Qi, Shandong Univ. of Science and Technology (China)

67881 A Application of ant colony optimization (ACO) algorithm to remote sensing image classification

Q. Dai, J. Liu, China Remote Sensing Satellite Ground Station (China)

6788 1B Extraction and trace of body joints in human motion capture system

T. Wang, G. Gong, L. Han, F. Yang, Beijing Univ. of Aeronautics and Astronautics (China)

6788 1C Parallel data processing based on image feature extraction in reverse measurement G. Li, Guangdong Ocean Univ. (China) and Harbin Univ. of Science and Technology (China); G. Liu, Tongji Univ. (China); L. Song, Harbin Univ. of Science and Technology (China); G. Tan, Guangdong Ocean Univ. (China) and Harbin Univ. of Science and Technology (China)

6788 1D Novel image matching confidence fusion evaluation algorithm based on support vector machine

L. Zou, Z. Cao, T. Zhang, Huazhong Univ. of Science and Technology (China)

$6788 \mathrm{IE} \quad$ Analysis of facial characteristics in spectropolarimetric imagery

Y. Zhao, Northwestern Polytechnical Univ. (China); L. Zhang, The Hong Kong Polytechnic Univ. (Hong Kong China); T. Yang, P. Wei, H. Yang, Northwestern Polytechnical Univ. (China)

$6788 \mathrm{IF} \quad$ Image categorization based on multi-scale vocabulary X. Yang, J. Tang, X. WU, Univ. of Science and Technology of China (China)

$67881 \mathrm{G}$ Novel framework for producing multi-scale and multi-viewpoint images based on remote sensing stereopair

Y. Tan, Z. Cao, Y. Li, Huazhong Univ. of Science and Technology (China) 
$6788 \mathrm{1H} \quad$ Learning framework for examiner-centric fingerprint classification using spectral features P. W. H. Kwan, Y. Guo, Univ. of New England (Australia); J. Gao, Charles Sturt Univ. (Australia)

$678811 \quad$ Large-scale building scenes reconstruction from close-range images based on line and plane feature

Y. Ding, J. Zhang, Wuhan Univ. (China)

$6788 \mathrm{IJ} \mathrm{High} \mathrm{resolution} \mathrm{remote} \mathrm{sensing} \mathrm{image} \mathrm{classification} \mathrm{with} \mathrm{multiple} \mathrm{classifiers} \mathrm{based}$ on mixed combining rule

Z. Chen, J. Liu, G. Wang, Q. Li, Huazhong Univ. of Science and Technology (China)

6788 IK 3D-reconstruction of a building from LIDAR data with first-and-last echo information

G. Zhang, Wuhan Univ. (China); J. Zhang, Chinese Academy of Surveying and Mapping (China); J. Yu, H. Yang, M. Tan, Wuhan Univ. (China)

$6788 \mathrm{lL} \quad$ Face recognition under variable lighting using local qualitative representations Y. Zhang, Y. Chu, X. Mou, G. Zhang, Huazhong Univ. of Science and Technology (China)

$67881 \mathrm{M}$ Object category recognition using boosting tree with heterogenous features L. Lin, Beijing Institute of Technology (China); C. Xiong, Huazhong Univ. of Science and Technology (China); Y. Liu, Y. Wang, Beijing Institute of Technology (China)

6788 iN Rating of web pages based on image content analysis

F. Xiao, M. Zhang, L. Tang, J. Zhou, Tsinghua Univ. (China)

678810 Time-stamped planar curves matching for reconstruction of aerocraft trajectories S. Wang, J. Wang, Radar Academy (China); T. Zhang, Huazhong Univ. of Science and Technology (China); G. Zhao, Huazhong Univ. of Science and Technology (China) and Wuhan Univ. of Technology (China)

6788 IP Polarimetric SAR image classification based on polarimetric decomposition and neural networks theory

H. Luo, L. Tong, X. Li, Y. Chen, X. Liu, M. Li, Y. Zhang, Univ. of Electronic Science and Technology of China (China)

6788 1Q Performance research of Gaussian function weighted fuzzy C-means algorithm X. Liu, Univ. Of Electronic Science and Technology of China (China) and Sichuan Univ. of Science and Engineering (China); X. Li, Univ. of Electronic Science and Technology of China (China); C. Yang, Sichuan Univ. of Science and Engineering (China); B. He, Y. Zhang, Univ. of Electronic Science and Technology of China (China)

6788 IR From primal sketch to 2.1D sketch with contour reorganization R. Gao, Huazhong Univ. of Science and Technology (China) and Lotus Hill Research Institute (China); N. Sang, Huazhong Univ. of Science and Technology (China)

6788 is On-line estimation of image Jacobian matrix by improved Broyden's method in uncalibrated visual servoing

X. Zeng, X. Huang, M. Wang, Huazhong Univ. of Science and Technology (China)

$67881 T \quad$ Research on automatic human chromosome image analysis

D. Ming, J. Tian, J. Liu, Huazhong Univ. of Science and Technology (China) 
$67881 \mathrm{U} \quad$ Line feature matching algorithm

T. Jin, C. Li, Xiamen Univ. (China)

$67881 \mathrm{~V}$ Three-dimensional reconstruction from the method of CAD-based photogrammetry L. Yang, S. Zheng, Wuhan Univ. (China)

6788 IW Stick-guided lateral inhibition for enhancement of low-contrast image

S. TU, Y. WU, X. LU, H. Huo, T. Fang, Shanghai Jiao Tong Univ. (China)

$67881 \mathrm{X} \quad$ Study on adaptive BTT reentry speed depletion guidance law based on BP neural network Z. Zheng, Y. Wang, H. Wu, Huazhong Univ. of Science and Technology (China) and Key Lab. of Ministry of Education for Image Processing and Intelligent Control (China)

$67881 \mathrm{Y} \quad$ Logo image clustering based on advanced statistics

Y. Wei, Wuhan Univ. of Technology (China); M. Kamel, Univ. of Waterloo (Canada); Y. He, Wuhan Univ. of Technology (China)

$678812 \quad$ Fuzzy selective voting classifier with defect extraction based on comparison within an image

T. Honda, R. Nakagaki, Hitachi Ltd. (Japan); O. Kenji, Hitachi High-Technologies Corp. (Japan); Y. Takagi, Hitachi Ltd. (Japan)

678820 Matching SAR image to optical image using modified Hausdorff distance and genetic algorithms

H. Mao, Huazhong Institute of Electro-Optics (China); Q. Yu, T. Zhang, Huazhong Univ. of Science and Technology (China)

678821 Object matching using weight Hausdorff distance matrix combined with genetic algorithm Q. YU, B. Yang, J. Liu, J. Tian, Huazhong Univ. of Science and Technology (China)

678822 Adaptive neural network nonlinear control for BTT missile based on the differential geometry method

H. Wu, Y. Wang, Huazhong Univ. of Science and Technology (China) and Key Lab. of Ministry of Education for Image Processing and Intelligent Control (China); J. Xu, Huazhong Univ. of Science and Technology (China)

678823 3D model retrieval based on K-means clustering H. Jing, M. Huang, Y. Zhong, Guilin Univ. of Electronic Technology (China)

678824 Efficient stellar spectral type classification for SDSS based on nonnegative matrix factorization

J. Yang, Beijing Univ. of Technology (China); Z. Liu, Beijing Jiaotong Univ. (China); F. Wu, Institute of Automation (China)

678825 Vision-based 3D registration of outdoor AR system

X. Wu, Wuhan Univ. (China) and China Univ. of Geosciences (China); Q. Du, F. Ren, T. Liu, Wuhan Univ. (China)

678826 Adaptive skin detection based on online training

M. Zhang, L. Tang, J. Zhou, G. Rong, Tsinghua Univ. (China) 
$678827 \quad$ Boosting bootstrap FLD subspaces for multiclass problem

T. Wang, D. Shen, L. Wang, N. Yu, Univ. of Science and Technology of China (China)

678828 Self-organizing shape from shading method based on hybrid reflection model

L. Tang, B. XU, H. Shi, Huazhong Univ. of Science and Technology (China)

678829 Research on multi-class classification of support vector data description

M. Shen, H. Xiao, Q. Fu, National Univ. of Defence and Technology (China)

6788 2A Adaptive K-means clustering algorithm

H. Chen, X. WU, J. Hu, Univ. of Science and Technology of China (China)

$67882 B$ Some properties of the fuzzy equivalence matrices

J. Zhang, B. Yang, X. Liu, X. Zhu, S. Zeng, Huazhong Univ. of Science and Technology

(China)

6788 2C Accuracy improvement for 3D shape measurement system based on gray-code and phase-shift structured light projection

X. Chen, J. Xi, Y. Jin, B. XU, Shanghai Jiao Tong Univ. (China)

6788 2D Improved bi-lateral filter in high dynamic range compression

Z. Li, Wuhan Univ. (China); J. Huang, Huazhong Univ. of Science and Technology (China);

Q. Wang, Wuhan Univ. (China)

$67882 \mathrm{E}$ Soluble solids contents measurement of grape juice beverage based on Vis/NIRS and chemomtrics

D. Wu, Y. He, Zhejiang Univ. (China)

$67882 \mathrm{~F} \quad$ New point matching algorithm for panoramic reflectance images

Z. Kang, S. Zlatanova, Delft Univ. of Technology (Netherlands)

$67882 \mathrm{G}$ Two dimensional LDA using volume measure in face recognition

J. Meng, Univ. of Electronic Science and Technology of China (China); L. Feng, Sichuan Province Inspection Test Bureau of Electronic Produces (China); X. Zheng, Institute of Automation (China)

$67882 \mathrm{H} \quad$ Forest fire and smoke detection based on video image segmentation

D. Zhang, A. Hu, Y. Rao, J. Zhao, J. Zhao, Wuhan Univ. (China)

6788213 3D surface texture synthesis using improved graph cuts

J. Dong, L. Li, S. Ma, Ocean Univ. of China (China)

6788 2J Robust face recognition using gradient map and Hausdorff distance measure

J. Chi, D. Chen, X. Lu, X. Li, HuaQiao Univ. (China)

6788 2K Slide projector calibration based on calibration of digital camera

J. Tao, Jianghan Univ. (China)

6788 2L Improved self-calibration algorithm of absolute dual quadric

M. Sun, Peking Univ. (China) 
$67882 \mathrm{M}$ Ontological concept extraction based on image understanding and describing of remote sensing domain

L. Zhong, H. Ma, P. Liu, Wuhan Univ. (China)

6788 2N Fuzzy-rough membership function neural network and its application to pattern recognition D. Zhang, Xiangtan Univ. (China); Y. Wang, Hunan Univ. (China); H. Huang, Xiangtan Univ. (China)

678820 Hyperspectal RS image classification based on kernel methods

G. Yang, H. Liu, X. Yu, Information Engineering Univ. (China)

6788 2P Object detection based on 2D canonical correlation analysis

G. Zhang, W. Zhou, W. Ren, S. Liu, Xidian Univ. (China)

$67882 Q \quad$ Visualization analysis platform based on land surface remote sensing radiation transfer characteristics

S. Wu, Univ. of Electronic Science and Technology of China (China) and Institute of Remote Sensing Applications (China) and Beijing Normal Univ. (China); Q. Liu, H. Huang, X. Xin, M. Chen, Institute of Remote Sensing Applications (China) and Beijing Normal Univ. (China)

$67882 \mathrm{R} \quad$ Algorithm of orthogonal bi-axle for auto-separating of watermelon seeds Y. Sun, M. Guan, D. YU, J. Wang, Soochow Univ. (China)

678825 Discrimination of rapeseed and weeds under actual field conditions based on principal component analysis and artificial neural network by VIS/NIR spectroscopy M. Huang, Y. Bao, Y. He, Zhejiang Univ. (China)

6788 2T Variety identification of brown sugar using short-wave near infrared spectroscopy and multivariate calibration

H. Yang, Zhejiang Univ. and Zhejiang Univ. of Technology; D. Wu, Y. He, Zhejiang Univ. (China)

$67882 \mathrm{U}$ Application of effective wavelengths and BP neural network for the discrimination of varieties of instant milk tea powders using visible and near infrared spectroscopy F. Liu, Y. He, L. Wang, Zhejiang Univ. (China)

6788 2V Feature extraction technology of 3D geometric model based on STEP-NC J. Zhou, T. Zhou, H. Pan, Nanchang Univ. (China)

Author Index 


\title{
Symposium Committees
}

\author{
Symposium Honorary Chair
}

Deren Li, Wuhan University (China)

Symposium Chair

Thomas S. Huang, University of Illinois at Urbana-Champaign (USA)

Symposium Cochair

Bo Zhang, Tsinghua University (China)

Program Committee

Chairs

Bir Bhanu, University of California, Riverside (USA)

Tianxu Zhang, Huazhong University of Science and Technology (China)

Members

Bir Bhanu, University of California, Riverside (USA)

C. H. Chen, University of Massachusetts, Dartmouth (USA)

Yenwei Chen, Ritsumeikan University (Japan)

Mingyue Ding, Huazhong University of Science and Technology (China)

Kunio Doi, University of Chicago (USA)

Jufu Feng, Beijing University (China)

Aaron Fenster, University of Western Ontario (Canada)

Junbing Gao, Charles Sturt University (Australia)

Thomas S. Huang, University of Illinois at Urbana-Champaign (USA)

Xinhan Huang, Huazhong University of Science and Technology (China)

Paul W.H. Kwan, University of New England (Australia)

Bangjun Lei, Smartree GmbH CTO (Switzerland)

Jun Li, University of Wisconsin, Madison (USA)

Lihua Li, Hangzhou Dianzi University (China)

Qiang Li, University of Chicago (USA)

Xuelong Li, University of London (United Kingdom)

Jianguo Liu, Huazhong University of Science and Technology (China)

Qinghuo Liu, Institute of Remote Sensing Applications, Chinese Academy of Sciences (China)

Hangqing Lu, Chinese Academy of Sciences (China)

Henri Maître, École Nationale Supérieure des Télécommunications

(France)

S. J. Maybank, University of London (United Kingdom)

Carl A. Nardell, Raytheon Santa Barbara Remote Sensing (USA)

Xiaochuan Pan, University of Chicago (USA)

Xubang Shen, Chinese Academy of Sciences (China) 
Duane D. Smith, Lockheed Martin Corporation (USA)

Enmin Song, Huazhong University of Science and Technology (China)

Hong Sun, Wuhan University (China)

Jie Tian, Chinese Academy of Sciences (China)

Friedrich Wahl, Technische Universitäł Braunschweig (Germany)

Chao Wang, China Remote Sensing Satellite Ground Station (China)

Patrick Wang, Northeastern University (USA)

Runsheng Wang, National University of Defense Technology (China)

Yongji Wang, Huazhong University of Science and Technology (China)

Jie Yang, Shanghai Jiaotong University (China)

Jingyu Yang, Nanjing University of Science and Technology (China)

Tianxu Zhang, Huazhong University of Science and Technology (China)

Jie Zhou, Tsinghua University (China)

Zhenfu Zhu, China Aerospace Machinery and Electronics Company (China)

Organizing Committee

Chair

Jianguo Liu, Huazhong University of Science and Technology (China)

Cochairs

Mingyue Ding, Huazhong University of Science and Technology (China)

Hanqing Lu, Institute of Automation, Chinese Academy of Sciences (China)

Enming Song, Huazhong University of Science and Technology (China)

Jinxue Wang, SPIE

General Secretary

Yuanming Geng, Huazhong University of Science and Technology (China)

Associate General Secretary

Faxiong Zhang, Huazhong University of Science and Technology (China)

Secretaries

Ting Guo, Jinhua Zhang, Min Bai, Ying Liu, Pingping Zhu, Pei Qin, Min Liu, Hualong Zhao, WenJuan Zheng 


\section{Preface}

Universities in Wuhan have a long history of outstanding research in multispectral image processing and related areas. Thus, it is most fitting that the Fifth International Symposium on Multispectral Image Processing and Pattern Recognition has chosen Wuhan as its venue. Professor Deren Li, Wuhan University, is one of the leading authorities in remote sensing in the world. We are very happy that he is honorary chair of the symposium. Wuhan was established about 3,500 years ago, and is of great importance in China's cultural, military, economical, and political history. There are many important historical sites within the city's limits. We hope that the participants of the symposium will not only be hard working at the conference, but also finding time to see some of these historical sites.

The Symposium has a broad charter. Instead of interpreting "multispectal" in its narrow sense of multiple-wavelength, we consider it in a very broad sense to include "multimodal" (e.g., audio and visual) and "multimedia" (e.g., text, graphics). In the 696 papers presented at this Symposium, we will find discussions on almost all aspects of this broad field. Important and novel tools in signal processing and machine learning will be presented and applied to remote sensing, GIS data processing, automatic target recognition, biometrics, medical imaging, and other problems. One crucial issue in multispectral/ multimodal/multimedia processing and analysis is: How do we fuse the cues from multiple sources? (There are three possibilities: Low- or feature-level fusion, middlelevel fusion, and high- or decision-level fusion.) This issue will be discussed in some of the papers.

The response to the call for papers was overwhelming. Around 1,400 papers were submitted, of which 696 were selected for presentation. The proceedings of the Symposium have 5 volumes:

- Automatic Target Recognition and Image Analysis; and Multispectral Image Acquisition

- Multispectral Image Processing

- Pattern Recognition and Computer Vision

- Medical Imaging, Parallel Processing of Images, and Optimization Techniques

- Remote Sensing and GIS Data Processing and Applications; and Innovative Multispectral Technology and Applications.

This Symposium provides a forum for scientists and engineers from universities, industry, and government labs to meet and exchange ideas. We expect that there will be ample discussions both inside and outside the lecture halls, and we can guarantee that this will be a most exciting event. 
The realization of a symposium depends on the hard work of many people. We would like to thank everyone on the organization committee, all of whom are responsible for making this conference a success.

Thomas S. Huang

Bo Zhang 